IRA-International Journal of Applied Sciences ISSN 2455-4499; Vol.07, Issue 03 (2017)

Institute of Research Advances

Pg. no. 103-110

https://research-advances.org/index.php/IRAJAS

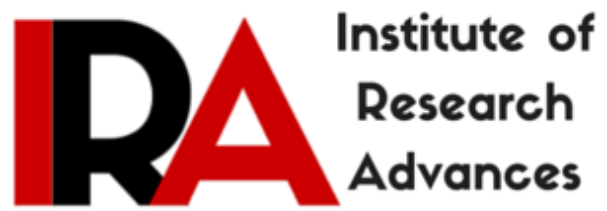

\title{
Analysis of Severe Pain and its Treatment in a Palliative Care Unit in a Regional Cancer Centre
}

Dr. Kannan P, (Senior Resident) ${ }^{1}$

Dr. Gunaseelan K, (Additional Professor) ${ }^{2}$

Dr. Parthasarathy V, (Additional Professor and Head) ${ }^{3}$

${ }^{1,2,3}$ Department of Radiotherapy, Regional Cancer Centre, JIPMER, Puducherry, India.

Type of Review: Peer Reviewed.

DOI: http://dx.doi.org/10.21013/jas.v7.n3.p1

\section{How to cite this paper:}

Kannan P., Gunaseelan K., Parthasarathy V. (2017). Analysis of Severe Pain and its Treatment in a Palliative Care Unit in a Regional Cancer Centre. IRA-International Journal of Applied Sciences (ISSN 2455-4499), 7(3), 103-110. doi:http://dx.doi.org/10.21013/jas.v7.n3.p1

(C) Institute of Research Advances

\section{(cc) EY-NC}

This work is licensed under a Creative Commons Attribution-Non Commercial 4.0 International License subject to proper citation to the publication source of the work.

Disclaimer: The scholarly papers as reviewed and published by the Institute of Research Advances (IRA) are the views and opinions of their respective authors and are not the views or opinions of the IRA. The IRA disclaims of any harm or loss caused due to the published content to any party. 


\section{ABSTRACT}

Objective: Pain is one of the most common symptoms that troubles cancer patients and precludes satisfactory quality of life. Globally, nearly $80 \%$ of the cancer patients receive little or no pain medication and cancer pain is barely controlled. This study was done to analyse the prevalence of pain and pain treatment in patients presenting to palliative care unit in a regional cancer centre.

Methods: Palliative care registry and follow-up forms of 2142 patients who got registered in our palliative care unit were analysed to obtain the demographic details, treatment characteristics and to determine the prevalence of pain, its severity, and treatment in cancer patients in our regional cancer centre.

Results: Nearly 50\% of the cancer population had head and neck and gastrointestinal tract malignancies and received only best supportive care. Stage IV disease was found in $40 \%$ of patients, and skeletal metastasis (52\%) was most common. This study showed a $92.4 \%$ prevalence of cancer pain in our centre. About $40 \%$ of patients with pain had a pain score of 7-10 by Numerical rating scale on initial presentation to the palliative care unit. About $65 \%$ of the patients with severe pain had a response to treatment withmorphine during their first follow-up to palliative care unit after initial registration. The average overall pain score of the patients per visit decreased from around 7 to 4 at a median follow-up of ten months.

Significance of results: Thus, there is a high prevalence of pain in cancer patients and patients with severe pain receive little or no opioid medication at all probably due to the lack of adequate education and training to the primary oncologists and residents regarding prescription of strong opioids. This audit may help in the modification of existing and formulation of new policies in the delivery of palliative care.
\end{abstract}

KEYWORDS: Pain; Severity of Pain; Palliative care

\title{
INTRODUCTION
}

WHO defines "Palliative care as an approach that improves the quality of life of patients and their families facing the problem associated with life-threatening illness, through the prevention and relief of suffering by means of early identification and impeccable assessment and treatment of pain and other problems, physical, psychosocial and spiritual"'[1]. Similar to cancer treatment, a multidisciplinary team encompassing physicians, nurses, social workers and many others is required to provide comprehensive palliative care. Palliative care, which initially started as hospice care in the 1970s, has now undergone rapid growth to become a sub-speciality of medicine.

Pain is one of the most common symptoms observed in cancer patients presenting to palliative care clinic. Most cancer patients experience some degree of pain, especially in advanced stages, precluding satisfactory quality of life. A systematic review found pain reported in $35-96 \%$ of cancer patients. The prevalence of pain is about $70 \%$ in advanced stage [2]. Cancer pain is treated following the WHO analgesic ladder [3]. WHO analgesic ladder is a three-step approach to the management of cancer pain. Despite the widespread recognition of guidelines for the treatment of cancer pain and increase in opioid consumption, a significant number of patients are still experiencing and suffering from cancer pain. Globally, $80 \%$ of the cancer population receive inadequate or no pain medication $[4,5]$.

A Palliative care clinic had been started in our regional cancer centre in 2012. In this article, we present a review of the medical records of the patients who got registered in our palliative care clinic, the status of their pain during initial and subsequent visits and detailed information on the use of strong opioids in our palliative clinic. This audit may help in the modification of existing and formulation of new policies in the delivery of palliative care. 


\section{METHODS}

All patients registered in our palliative care clinic from 2012 to 2015 were taken into this retrospective cross-sectional study. A palliative care registry form was completed for each patient entering into palliative care clinic by a health care professional. The form contained information on demographics, age, gender, diagnosis, the presence of distant metastases. The following data were also obtained from the registry and follow-up forms: symptoms reported by the patient, pain scores, pain medications and their doses. All data are descriptive in character and described using frequency tables with counts and percentages.

\section{RESULTS}

The palliative care records of 2142 patients who got registered in our regional cancer centrewere reviewed. The patient characteristics regarding age, sex, primary site, stage and metastases are shown in Table 1 . Out of 2142 patients, $52 \%$ were males. The median age was 55 . The majority of patients were in the age group of 40-60 years. Figure 1 shows the age distribution of the patients. About $98.5 \%$ of patients had malignant disease. The most common primary site was head and neck (32\%) followed by gastrointestinal tract cancers (19\%). Bones (52\%) and lungs (32\%) were the most common sites of distant metastases.

Table 2 shows the various modalities of treatment received by the patients registered in our palliative care unit. Nearly one-half of the patients received only best supportive care. About $23 \%$ of patients received only palliative radiotherapy, and $12 \%$ of patients received only chemotherapy. The most common symptom reported by patients attending our palliative care clinic is pain (92\%). Other major symptoms include insomnia (76\%), loss of appetite (70\%), weight loss $(72 \%)$ and constipation $(69 \%)$ as shown in Table 3.

The prevalence of pain is $92.8 \%$ in our cancer patients. About $40 \%$ of patients with pain had the pain of severe intensity (pain score of 7-10 on the numerical rating scale) at initial presentation to palliative care clinic. Patients with mild to moderate pain were prescribed paracetamol, non-steroidal anti-inflammatory drugs (NSAIDS), weak opioids (tramadol) and other adjuvant analgesics like tricyclic antidepressants if required. Patients with severe pain received morphine. About $65 \%$ of the patients with severe pain had a response to treatment withmorphine during their first follow-up to palliative care unit after initial registration. At the time of this study, there were 571 patients receiving morphine for severe pain; the rest of the patients with severe pain were either dead or lost to followup. Figure 2 shows the distribution of daily doses of morphine for these patients. The majority of patients received morphine doses ranging from 30-60 mg. The average overall pain score of the patients per visit decreased from around 7 to 4 at a median follow-up of ten months as depicted in figure 3 .

\section{DISCUSSION}

Pain is defined as an "unpleasant sensory and emotional experience associated with actual or potential tissue damage, or described in terms of such damage"[6]. Pain is influenced by many factors including emotional, cognitive and spiritual. It is not possible definitively to identify whether the pain that occurs is associated with actual tissue damage or not [7].

According to this study, the prevalence of pain in patients referred to our palliative unit is $92.8 \%$, and nearly $40 \%$ of the patients had the pain of severe intensity by numerical rating scale [NRS score of 7-10]. Overall, the literature suggests that pain is one of the most feared symptoms in cancer patients and there are wide variations in reported prevalence [8]. A systematic review showed that the prevalence of pain in cancer patients ranges from 35-96\% [2,9]. The possible cause for this significant variation in prevalence is that these studies are conducted in different sets of the population and variedsettings, and so, it is hard to generalise these findings. Moreover, there is no standard method available to assess whether a patient has pain or not and its severity $[2,10,11]$. 
Our study revealed that the majority of patients with severe pain were treated with only NSAIDS and weak opioids at the time of presentation to palliative care unit; only a few patients received strong opioids like morphine; this shows that the primary physicians have inadequately treated pain. The literature also confirms our findings that pain is still prevalent in cancer patients and it has been inadequately treated. In a study by Cleeland et al.[5], about $42 \%$ of the patients with pain did not receive adequate pain medications. The IASP Task Force on cancer pain survey also demonstrated the inadequacy of cancer pain treatment [4]. The possible reasons for high prevalence, and poor cancer pain treatment by the primary physicians could be the opiophobia, the lack of adequate education and training for the prescription of strong opioids, or some patient related barriers $[12,13]$.

The World Health Organisation [WHO] approach is a three-step approach to the management of cancer pain. According to this method, patients with mild cancer pain are treated with paracetamol and NSAIDs; patients with moderate pain and mild pain refractory to NSAIDs are treated with weak opioids like tramadol; patients with severe pain or moderate pain not responding to weak opioids are treated with strong opioids like morphine. Adjuvant analgesics like corticosteroids, tricyclic antidepressants are prescribed when required. Literature analysis shows that patients with severe pain started on strong opioids as first-line therapy had better pain relief and required fewer changes in treatment. Our results are similar as reported in the literature. In our study, we found that about $60 \%$ of patients with severe pain had adequate pain relief after starting morphine [14,15].

The limitations of this study include those that are observed in any retrospective study. The health care personnel makes the assessment of pain in this study; usually, observer assessments underestimate pain intensity. Moreover, the study may not reflect the actual prevalence of severe pain in the regional cancer centre since all patients with severe pain are not referred to the palliative care unit.

In conclusion, thus, there is a high prevalence of pain in cancer patients presenting to our palliative care unit. Patients with severe pain receive little or no opioid medication at all by the primary care doctors probably due to the lack of adequate education and training to the primary oncologists and residents regarding prescription of strong opioids.

\section{ACKNOWLEDGMENT}

We would like to thank -JivDaya Foundation, Dallas, Texas, USA for their support in Palliative Care.

\section{REFERENCES}

(1) Caraceni A. An international survey of cancer pain characteristics and syndromes. IASP Task Force on Cancer Pain. International Association for the Study of Pain. 1999.

(2) Classification of chronic pain. Descriptions of chronic pain syndromes and definitions of pain terms. Prepared by the International Association for the Study of Pain, Subcommittee on Taxonomy. 1986.

(3) Cleeland CS, Gonin R, Hatfield AK et al. Pain and its treatment in outpatients with metastatic cancer. N Engl J Med 1994;330(9):592-596.

(4) Foley KM.Pain assessment and cancer pain. In: Doyle D, Hanks G, MacDonald N, ed. Oxford textbook of palliative medicine. Oxford: Oxford University Press; 1998:140-8.

(5) Grond S, Zech D, Diefenbach C, Bischoff A. Prevalence and pattern of symptoms in patients with cancer pain: a prospective evaluation of 1635 cancer patients referred to a pain clinic. J Pain Symptom Manage 1994;9(6):372-382.

(6) Higginson IJ, Hearn J. A multicenter evaluation of cancer pain control by palliative care teams. $J$ Pain Symptom Manage 1997;14(1):29-35.

(7) Mercadante S, Fulfaro F. World Health Organization guidelines for cancer pain: a reappraisal. Ann Oncol 2005;16 Suppl 4:iv132-iv135.

(8) Paice JA, Toy C, Shott S. Barriers to cancer pain relief: fear of tolerance and addiction. J Pain Symptom Manage 1998;16(1):1-9. 
(9) Portenoy RK. Cancer pain. Epidemiology and syndromes. Cancer 1989;63(11 Suppl):2298-2307.

(10) Solano JP, Gomes B, Higginson IJ. A comparison of symptom prevalence in far advanced cancer, AIDS, heart disease, chronic obstructive pulmonary disease and renal disease. J Pain Symptom Manage 2006;31(1):58-69

(11) van den Beuken-van Everdingen MH, de Rijke JM, Kessels AG, Schouten HC, van KM, Patijn J. Prevalence of pain in patients with cancer: a systematic review of the past 40 years. Ann Oncol 2007;18(9):1437-1449.

(12)WHO. Cancer Pain Relief. 1998. Ref Type: Generic

(13) Wootton M. Morphine is not the only analgesic in palliative care: literature review. J Adv Nurs 2004;45(5):527-532.

(14) World Health Organization. WHO definition of palliative care. 2016. Ref Type: Online Source.

(15) Zenz M, Willweber-Strumpf A. Opiophobia and cancer pain in Europe. Lancet 1993;341(8852):1075-1076. 
(Tables \& Figures)

Table 1: Patient characteristics

\begin{tabular}{|c|c|c|}
\hline Characteristic & Number & Percentage \\
\hline Total cases & 2142 & \\
\hline \multicolumn{3}{|l|}{ Age(in years) } \\
\hline Median & 55 & \\
\hline Range & $13-74$ & \\
\hline \multicolumn{3}{|c|}{ Sex } \\
\hline Male & 1111 & 52 \\
\hline Female & 992 & 46 \\
\hline Unknown & 39 & 2 \\
\hline Total cancer cases & 2112 & \\
\hline \multicolumn{3}{|c|}{ Primary site } \\
\hline Head and neck & 681 & 32 \\
\hline Gastrointestinal tract & 402 & 19 \\
\hline Lung & 208 & 10 \\
\hline Gynaecological & 241 & 11 \\
\hline Breast & 187 & 9 \\
\hline Urological & 62 & 3 \\
\hline Others & 243 & 12 \\
\hline Unknown & 88 & 4 \\
\hline \multicolumn{3}{|c|}{ Stage } \\
\hline II & 16 & 1 \\
\hline III & 54 & 2 \\
\hline IV & 840 & 40 \\
\hline Unknown & 1202 & 57 \\
\hline \multicolumn{3}{|c|}{ Metastases } \\
\hline Total & 840 & \\
\hline Lung & 270 & 32 \\
\hline Liver & 130 & 16 \\
\hline Bone & 440 & 52 \\
\hline
\end{tabular}

Table 2: Treatment characteristics

\begin{tabular}{|l|r|r|}
\hline Characteristic & \multicolumn{1}{|l|}{ Number } & \multicolumn{1}{|c|}{ Percentage } \\
\hline No treatment & 1039 & 49 \\
\hline RT only & 489 & 23 \\
\hline CT only & 257 & 12 \\
\hline Surgery only & 69 & 3 \\
\hline S+RT & 37 & 2 \\
\hline S+CT & 36 & 2 \\
\hline S+RT+CT & 44 & 2 \\
\hline RT+CT & 141 & 7 \\
\hline
\end{tabular}


Table 3: Overall pattern of symptom presentation and severity

\begin{tabular}{|l|r|r|r|r|}
\hline Symptom & \multicolumn{3}{|c|}{ Severity } & Total \\
\hline & Mild & \multicolumn{1}{|c|}{ Moderate } & Severe & \\
\hline Pain & 313 & 859 & 780 & 1952 \\
\hline Insomnia & 308 & 1186 & 106 & 1600 \\
\hline Loss of appetite & 573 & 801 & 98 & 1472 \\
\hline Weight loss & 610 & 810 & 106 & 1526 \\
\hline Constipation & 326 & 1049 & 84 & 1459 \\
\hline Swelling & 325 & 658 & 259 & 1242 \\
\hline Breathlessness & 292 & 448 & 87 & 827 \\
\hline Nausea & 116 & 227 & 32 & 375 \\
\hline Vomiting & 99 & 518 & 303 & 920 \\
\hline Swallowing difficulty & 114 & 238 & 132 & 484 \\
\hline Cough & 311 & 373 & 42 & 726 \\
\hline Tiredness & 78 & 166 & 59 & 303 \\
\hline Urinary symptoms & 118 & 188 & 39 & 345 \\
\hline Oral candidiasis & 80 & 107 & 30 & 217 \\
\hline Stomatitis & 15 & 56 & 54 & 125 \\
\hline Bleeding & 35 & 70 & 12 & 117 \\
\hline Depression & 62 & 54 & 7 & 123 \\
\hline Headache & 246 & 366 & 32 & 644 \\
\hline Confusion & 11 & 45 & 3 & 59 \\
\hline Lymphedema & 27 & 64 & 11 & 102 \\
\hline Diarrhoea & 26 & 64 & 10 & 100 \\
\hline Anxiety & 4 & 28 & 4 & 36 \\
\hline
\end{tabular}

Figure 1: Age distribution (x-axis: age group; y axis - number of cases)

\section{Age distribution}

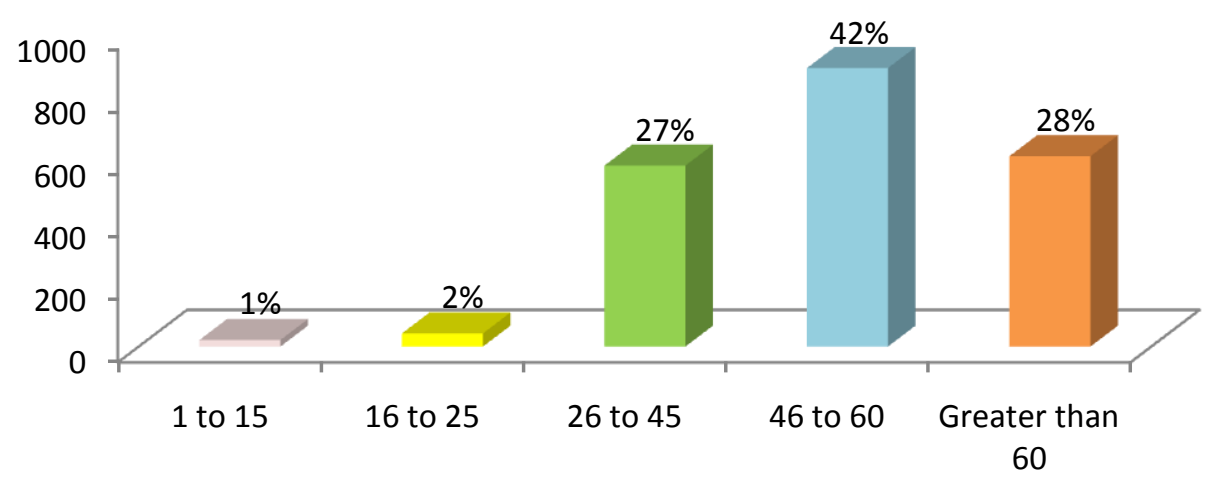


Figure 2: Distribution of daily doses of morphine for patients with severe pain

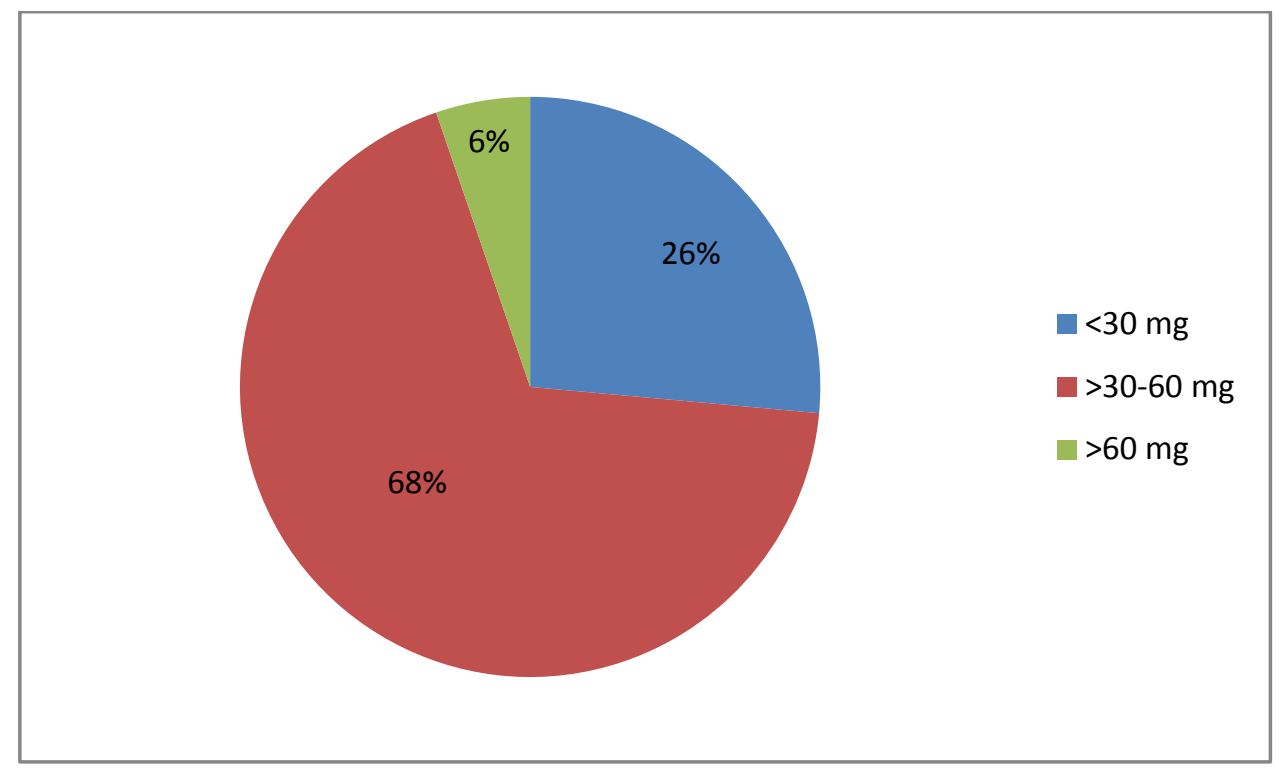

Figure 3: Average overall pain score

\section{Average Patient Overall Pain per Visit Number}

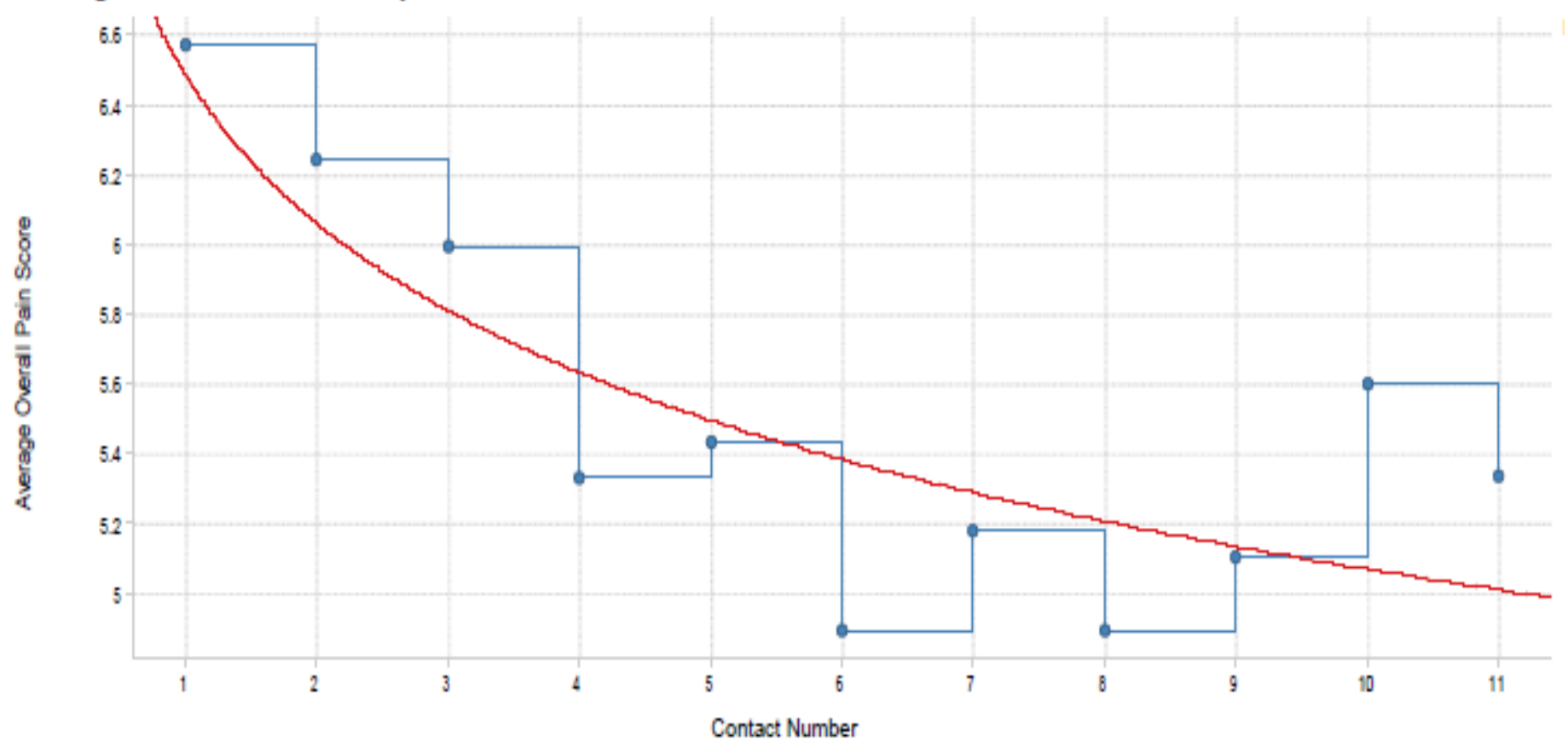

